\title{
DUELO DAS SOLUÇÕES: LÚDICO COMO FERRAMENTA PARA O ENSINO DE QUÍMICA
}

\author{
IRLEANE EDUARDO DA SILVA ${ }^{\mathbf{1}}$, JOCIVANE DE JESUS FURTADO ${ }^{2}$, \\ LEANDRO TAVARES ANSELMO ${ }^{3}$, SANDRA ALVES CAITANO DE \\ MENEZES ${ }^{4}$, KLENICY KAZUMY DE LIMA YAMAGUCHI ${ }^{5}$.
}

\begin{abstract}
1Graduanda em Ciências: Biologia e Química, Instituto de Saúde e Biotecnologia da Universidade Federal do Amazonas, Coari, Amazonas, Brasil. pequenafani01@gmail.com

2 Graduanda em Ciências: Biologia e Química, Instituto de Saúde e Biotecnologia da Universidade Federal do Amazonas, Coari, Amazonas, Brasil. joicifurtado05.rv@gmail.com

3 Graduanda em Ciências: Biologia e Química, Instituto de Saúde e Biotecnologia da Universidade Federal do Amazonas, Coari, Amazonas, Brasil. leolucasozakipf@gmail.com 4 Professora da SEDUC-AM, Graduanda em Ciências: Biologia e Química, Instituto de Saúde e Biotecnologia da Universidade Federal do Amazonas, Coari, Amazonas, Brasil. sandramenezes10@outlook.com 5 Doutora e mestre em Química, professora Adjunta no Instituto de Saúde e Biotecnologia da Universidade Federal do Amazonas, Coari, Amazonas, Brasil. Email: klenicy@ gmail.com
\end{abstract}

\section{RESUMO}

O objetivo deste trabalho foi utilizar a ludicidade no ensino de Química por meio de um jogo intitulado "Duelo das soluções químicas". Esta atividade foi aplicada no segundo ano do Ensino Médio em uma escola pública no interior do Amazonas e buscou despertar a competitividade e o interesse dos alunos em aprender e compreender melhor o conteúdo sobre soluções químicas. A atividade foi realizada utilizando o jogo de trilhas e cartas. O lúdico pôde demonstrar que o professor deve sempre inovar sua prática pedagógica para ensinar química aos alunos, possibilitando que eles possam adquirir o aprendizado significativo e contínuo, sendo disseminadores do conhecimento, compartilhando suas aprendizagens com os pais, amigos e a sociedade como um todo.

Palavras-chave: Ensino de Química; Residência Pedagógica; Lúdico.

\section{DUELO OF SOLUTIONS: LUDIC AS A TOOL FOR TEACHING CHEMISTRY}

\begin{abstract}
The aim of this work was the use ludic games involving "Duelo of chemical solutions" as content. This activity was applied in the second year of high school in a public school in the interior of Amazonas. It was sought to awaken the competitiveness and interest of students in learning and better understanding the content about chemical solutions. The activity was carried out using the game of tracks and cards. The ludic activity was able
\end{abstract}


to demonstrate that the teacher should always innovate his pedagogical practice to teach chemistry to students, enabling him to acquire meaningful and continuous learning, being disseminators of knowledge, sharing his learning with parents, friends and the whole community.

Keywords: Teaching Chemistry; Pedagogical Residence; Ludic.

\section{INTRODUÇÃO}

A química está presente em nossas vidas diariamente e é essencial para a sobrevivência humana, contribuindo com o entendimento e com a compreensão do mundo no seu sentido material, em como tudo se constitui e se transforma e o que envolve essas transformações (OLIVEIRA, GOUVEIA e QUADROS, 2009, p. 24).

Schnetzler (2002) informa que os conhecimentos químicos nem sempre são apropriados de maneira simples e direta, fazendo com que, devido a falta de compreensão, tornem-se assuntos abstratos e difíceis para os alunos do ensino regular. Nesse contexto, o professor tem papel primordial: ser mediador do conhecimento teórico e contribuir para a aprendizagem dos discentes.

Para tanto, pesquisas vêm sendo publicadas em revistas de educação e congressos científicos com o objetivo de contribuir para o ensino de química, principalmente das áreas consideradas mais difíceis, que envolve a teoria aplicada a cálculos matemáticos. Entre as atividades descritas, tem-se o uso de atividades experimentais, lúdicas, uso de Tecnologia de informação e Comunicação (TIC) e outras atividades que despertem o interesse dos estudantes (FERREIRA et al., 2012; QUEIROZ, ROCHA e YAMAGUCHI, 2018; CRESPO e GIACOMINI, 2019).

No segundo ano do Ensino Médio, tem-se o assunto de soluções, em que os alunos encontram dificuldade para compreender a teoria associada a fórmulas e a cálculos. Se essa dificuldade não for sanada, as consequências podem se perdurar por toda a vida do indivíduo, tendo em vista que diluições e elaboração de soluções estão presentes em diversas atividades do cotidiano.

Segundo a Base Nacional Comum Curricular do Ensino Médio (BNCC-EM), o ensino deve contemplar uma aprendizagem marcada pelas interações diretas com os fenômenos, os fatos e as coisas, apropriando o discente nos procedimentos e linguagens que o preparem a resolver problemas em diversos contextos, ampliando o entendimento sobre os acontecimentos que ocorrem no cotidiano (BNCC, 2018). 
Pensando nesse contexto, o presente artigo propõe a inserção de um jogo lúdico para contribuir com o aprendizado dos alunos relacionado ao conteúdo "soluções". A utilização de jogos é um importante recurso didático por proporcionar uma metodologia diferenciada na relação ensino-aprendizagem. No caso da química, eles proporcionam uma experiência prática ao abordar conhecimentos em contextos específicos e a familiarização da linguagem química, ampliando no aluno as suas habilidades e capacidade de compreensão dos conceitos (CUNHA, 2012).

Assim sendo, o presente trabalho teve como objetivo geral propor um projeto de intervenção utilizando as atividades lúdicas para auxiliar na compreensão dos conceitos de soluções, dispersões, suspensões e coloides, ensinados no capítulo introdutório da disciplina de química no segundo ano do Ensino Médio. Propõe-se, com isso, facilitar o aprendizado, desmistificando e despertando o interesse e a curiosidade, a fim de ensinar os alunos a reconhecerem esses assuntos no seu cotidiano.

\section{MATERIAL E MÉTODOS}

A realização deste jogo lúdico deu-se no período de outubro a dezembro de 2019, na Escola Estadual Instituto Bereano de Coari. O critério de seleção foi o aceite em fazer parte desta pesquisa. Sendo assim, participaram como sujeitos 108 discentes do ensino médio que estavam regularmente matriculados.

O trabalho executado caracteriza-se como uma pesquisa de campo, apresentando a aplicação de uma metodologia didática aplicada ao ensino de Química. A seleção do tema deste trabalho surgiu com o desejo de contribuir com um assunto em que a docente da disciplina e também preceptora dos residentes, considerava que os discentes apresentavam dificuldade.

O conteúdo do jogo lúdico foi voltado como revisão do assunto soluções químicas. Para tanto, organizaram-se os materiais necessários para a produção de duas atividades: 1) Jogo de Cartas e 2) Trilha das soluções. Para a confecção das duas atividades, usou-se folhas A4 em branco, caneta, cola, tesoura e papelão. Colaram-se as folhas nas cartas para confecção de 15 (quinze) cartas com questões sobre o conteúdo, $10(\mathrm{dez})$ cartas com prendas, e 15(quinze) cartas com imagens relacionadas às questões. Para a trilha, utilizaram-se 10 retângulos de papelões contendo números referentes a ordem de um a dez e um dado elaborado com material reciclável. 
A metodologia da ludicidade utilizada neste projeto de intervenção foi definida em consenso entre os residentes e a preceptora, assim, o duelo de soluções deu-se como uma competição entre grupos pré-definidos em cada uma das três turmas do segundo ano do ensino médio e foram realizadas em 3 etapas:

a) Explanação teórica: Para iniciar o jogo, foi feita uma revisão do assunto pelos residentes, com duração de dois tempos de quarenta e cinco minutos, abordando o conteúdo com a utilização do livro didático e frisando os conceitos de solução, coloides, suspensão.

b) Atividade lúdica: Antes de iniciar a dinâmica do jogo lúdico, cada grupo escolheu seu representante para andar pela trilha e outro para pegar a carta. Para dar seguimento à atividade, fez-se um pequeno sorteio para verificar qual o grupo que iniciaria respondendo às perguntas. As cartas das questões estavam em uma mesa e as cartas das prendas e punições, separadas em outra mesa, na qual não havia alunos. As cartas estavam todas misturadas, sendo impossível ver seu conteúdo no momento de escolha pelo representante do grupo.

Regras: Segundo as regras do jogo, o jogador representante só andava nas casas pré-definidas após jogar o dado e acertar a resposta. Caso ele errasse a resposta, não avançava de base, apenas cumpriria a prenda. Os alunos não poderiam usar nenhum tipo de material de consulta e todos os grupos estavam competindo entre si.

As questões utilizadas foram:

O que são dispersões? O que compõe uma dispersão? Defina soluções. Identifique duas condições para ser considerada uma solução verdadeira? O que é uma solução sólida? Defina como ocorre uma solução gasosa? Qual o conceito de suspensões? Indique quais condições são necessárias para ser considerada uma suspensão? $O$ que são dispersões coloidais? Diferencie coloides hidrófobos de colides hidrófilos? A que se refere o processo de pectização? O que significa peptização? Explique o que é o efeito tyndall? $O$ que são micelas? Cite ao menos um exemplo de cada um dos tipos de dispersões estudados.

c) Avaliação da atividade: Após a realização do jogo lúdico, realizou-se a avaliação da atividade por meio de um questionário com 5 (cinco) perguntas para analisar a compreensão do assunto pelos alunos através do lúdico. 


\section{RESULTADOS E DISCUSSÃO}

A proposta de intervenção consistiu na aplicação de dois jogos lúdicos sobre a temática "soluções". Este assunto foi ministrado pelos próprios residentes no início do ano letivo, supervisionados pelo professor preceptor da disciplina. Observou-se que os alunos tinham dificuldade na compreensão do conteúdo soluções químicas, principalmente na aplicação dos cálculos de diluição e na classificação dos tipos de solução.

Diante da problemática detectada, planejou-se a elaboração de uma atividade de intervenção objetivando motivar os discentes e contribuir com a aprendizagem do conteúdo. Segundo Grando (2001), os jogos lúdicos beneficiam a aprendizagem de conteúdos já ensinados anteriormente e de forma mais motivadora, admitindo assim uma melhor aprendizagem e desenvolvimento de táticas que permitem a resolução de problemas, além de propiciar a interação e participação dos discentes, contribuindo com seu próprio conhecimento.

Foi realizada a aula expositiva de revisão sobre o tema, em que os alunos já tinham conhecimentos prévios sobre os conteúdos abordados, o que ocasionou o impacto positivo, aumentando o interesse dos alunos na participação da atividade.

Durante a revisão teórica, pode-se observar a dificuldade dos discentes relacionadas ao tema. Verificou-se que, embora não tivesse sido um assunto inédito, as turmas apresentavam dúvidas sobre o capítulo, principalmente relacionadas aos cálculos, equações e aplicabilidade dos conceitos, não conseguindo reconhecer nas soluções utilizadas no cotidiano, as diferenças entre suspensões, dispersões e outros. De acordo com Marcelino (1996, p.38), apesar das fórmulas serem importantes, faz-se necessário a compreensão do assunto, relacionando assim, com a aplicação na vida real.

A execução do projeto de intervenção ocorreu na área da cantina por ser um local com espaço maior, comportando mais alunos, em comparação com a sala de aula. Os representantes na trilha jogavam o dado e a residente fazia a pergunta que se encontrava na carta selecionada por um integrante da equipe. Somente a resposta correta permitia que o representante andasse as casas da trilha, conforme valor encontrado ao lançar o dado. Pode-se observar, na figura 1, os materiais didáticos utilizados e a execução da atividade. 
Figura 1- Atividades realizadas no duelo das soluções. A) cartas, B) trilha, C) realização do jogo e D) disposição de alguns dos grupos e participação da residente na atividade.

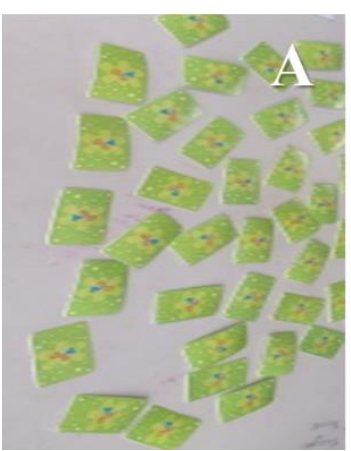

Fonte: Eduardo, 2019
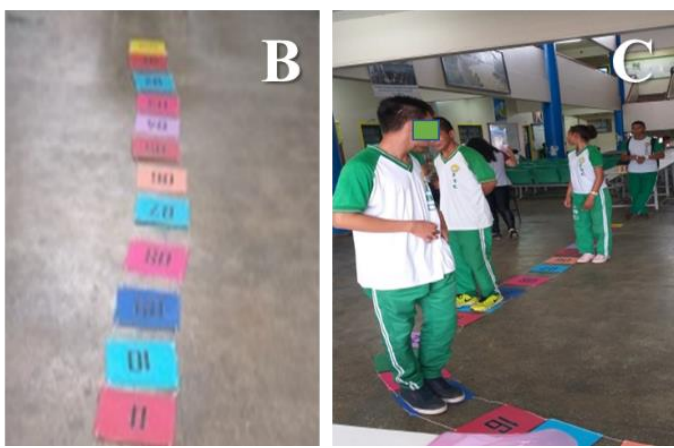

Fonte: Eduardo, 2019.

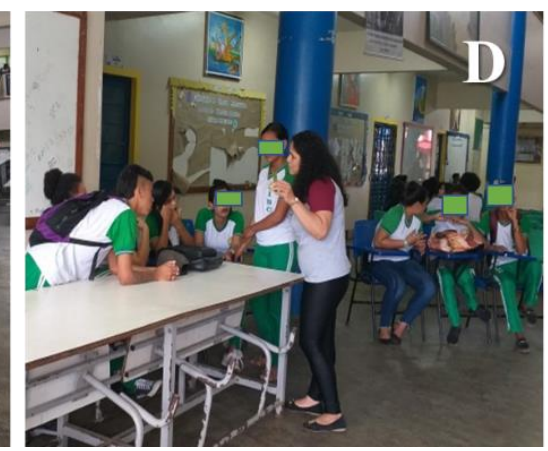

Observou-se que os alunos estavam entusiasmados com a competição e todos os grupos possuíram um bom desempenho nas questões, estavam bem desinibidos e realizavam as prendas sem timidez. A competitividade entre os grupos demonstrou o ânimo de grande parte dos alunos que, mesmo com as dificuldades, esforçavam-se para responder as questões e ajudar o representante da equipe. Foi perceptível que a atividade influenciou de forma benéfica a capacidade dos discentes em trabalhar em equipe, além de sedimentarem o conteúdo abordado.

$\mathrm{O}$ mais simples dos jogos pode possibilitar grandes benefícios àqueles que se comprometem a fazer parte da interação proporcionada pela atividade realizada, desenvolvendo habilidades como autoconfiança, destreza e competência (FERNANDES, FURQUIM e BARANAUSKAS, 1995).

A partir dos resultados obtidos, pode-se evidenciar que o uso das atividades lúdicas contribuiu com a assimilação dos conteúdos abordados, confirmados de forma quantitativa por meio das respostas do questionário de avaliação. Os resultados podem ser visualizados na tabela 1 .

Tabela 1- Avaliação da atividade lúdica.

\section{QUESTÕES}

1.Você entendeu o jogo?
ALTERNATIVAS RESPOSTAS (\%)

SIM

100

NÃO 


\begin{tabular}{|c|c|c|}
\hline $\begin{array}{l}\text { 2.Em sua opinião, as aulas } \\
\text { contextualizadas e o jogo lúdico } \\
\text { ajudam no processo de aprendizagem } \\
\text { dos conteúdos? }\end{array}$ & $\begin{array}{l}\text { SIM } \\
\text { NÃO }\end{array}$ & 100 \\
\hline $\begin{array}{l}\text { 3. Você gostaria que fossem aplicados } \\
\text { mais jogos lúdicos na sala de aula? }\end{array}$ & $\begin{array}{l}\text { SIM } \\
\text { NÃO }\end{array}$ & $\begin{array}{l}75 \\
25\end{array}$ \\
\hline $\begin{array}{l}\text { 4. Como aluno, você acredita que } \\
\text { poderia aprender com mais facilidade } \\
\text { os conteúdos de química se tivesse } \\
\text { metodologias alternativas, como o } \\
\text { lúdico e o experimental? }\end{array}$ & $\begin{array}{l}\text { SIM } \\
\text { NÃO }\end{array}$ & $\begin{array}{l}100 \\
0\end{array}$ \\
\hline $\begin{array}{l}\text { 5. Você acredita ser importante que o } \\
\text { professor busque inovar as aulas de } \\
\text { química como práticas experimentais } \\
\text { ou jogos lúdicos? }\end{array}$ & $\begin{array}{l}\text { SIM } \\
\text { NÃO }\end{array}$ & $\begin{array}{l}100 \\
0\end{array}$ \\
\hline
\end{tabular}

Fonte: As autoras (2020).

$\mathrm{Na}$ primeira e segunda questão, os alunos foram unânimes em afirmar que compreenderam o jogo e que este facilitou no entendimento sobre o assunto. A terceira questão buscou identificar se os alunos gostariam que fosse realizadas mais atividades lúdicas na sala de aula, e $75 \%$ dos alunos disseram que sim, enquanto $25 \%$ não concordaram. Esse percentual de rejeição pode ser atribuído ao fato de alguns alunos afirmarem informalmente que tinham a preferência para realização de aulas práticas experimentais.

$\mathrm{Na}$ questão quatro e cinco, identificou-se a preferência dos discentes por metodologias alternativas, sendo unânime a afirmativa de que eles gostariam que fosse realizadas atividades diferenciais e que consideram importante a busca dos docentes por aulas diferenciadas.

Diante da aplicação desse projeto de intervenção, evidencia-se da necessidade de práticas pedagógicas diferenciais para um melhor processo de ensino dos conteúdos considerados mais difíceis. Essa forma de ensinar, brincando, facilita a relação aluno/professor contribuindo com a motivação, interação e a competitividade de maneira saudável entre os envolvidos. 
No ensino de química, o uso de atividades lúdicas proporciona uma experiência prática ao abordar conhecimentos em contextos específicos e a familiarização da linguagem química, ampliando no aluno as suas habilidades e capacidade de compreender conceitos. Contudo, Cunha (2012) ressalta a importância das atividades não serem utilizadas com o objetivo de memorização do conteúdo ministrado ou com apenas a ótica da diversão, sendo necessária a mediação para a aplicação de assuntos que possam contribuir com o desenvolvimento e aprendizagem dos participantes.

A experiência adquirida foi uma maneira de inspiração para que os futuros professores pudessem desenvolver atividades além da sala de aula e pudessem levar essa vivência independente da disciplina, mostrando ser possível fazer uma aula conciliando o aprender e o lúdico.

$\mathrm{Na}$ produção do jogo lúdico, mediante a participação em sua confecção e execução da atividade, os alunos do projeto Residência Pedagógica em Química puderam vivenciar as dificuldades e adquirir experiência da prática de execução de um projeto, tornando-os assim, criadores de uma identidade própria na docência.

Esse foi um momento oportuno que acarretou troca de conhecimento e experiência não somente para os residentes, mas pode-se ter um retorno produtivo para todos os participantes envolvidos. Para os alunos do ensino regular, trouxe conhecimento de maneira diferenciada, através de brincadeiras e de uma competição que buscou expor e mostrar a facilidade na compreensão de um assunto complexo.

Para a professora preceptora, foi um momento oportuno para contribuir com sua experiência e conhecimento na formação de futuros colegas de profissão, visto que ela acompanhou em todos os momentos as ações dos residentes, buscando direcioná-los para o melhor caminho a seguir, ajudando durante as regências, e de certa maneira, sendo fundamental no processo de formação da identidade docente dos residentes.

Muito se tem discutido sobre a aplicação de metodologias didáticas para o ensino de Química. Na literatura, encontra-se muitas possibilidades disponíveis em livros, artigos e meios eletrônicos. Verifica-se que, embora exista um grande arsenal de materiais, ainda há o ensino tradicional, em que o livro didático e o quadro são os únicos procedimentos de ensino.

Os autores deste trabalho não menosprezam a importância dessas metodologias, levando em consideração que o aprendizado ocorre de forma individual, e que cada 
aluno tem uma familiaridade com determinado método. A discussão incita na necessidade de estimular, despertar a curiosidade e induzir os docentes a explorarem os conteúdos de forma contextualizada e buscando metodologias que possam agregar o conhecimento.

Espera-se que, por meio desses resultados, metodologias didáticas diferenciadas possam ocorrer com mais frequência, não somente na escola em que essa atividade foi realizada, mas para os leitores em que essa divulgação científica abranger, contribuindo com o desenvolvimento do ensino de Química e demonstrando que os conteúdos teóricos escolares ultrapassam a barreira física de uma sala de aula.

\section{CONSIDERAÇÕES FINAIS}

Por meio da atividade de intervenção, foi possível refletir sobre a importância da utilização de atividades lúdicas no processo educativo como instrumento facilitador da integração, sociabilidade, trabalho em equipe e, principalmente, do aprendizado, enfocando a necessidade de alguns cuidados que devem ser tomados ao levarmos a ludicidade em sala de aula e ressaltando a importância da colocação de regras e direcionamento docente.

Consideramos que este tipo de atividade permitiu que os alunos se familiarizem ou revisassem o assunto de soluções, contribuindo para que o ensino não ficasse extenso, decorativo e cansativo. Diante disso, pode-se utilizar uma metodologia didática para contribuir com a aprendizagem do conteúdo teórico.

Esse projeto de intervenção desempenhou um papel muito importante para todos os envolvidos, principalmente para os residentes que adquiriram experiências através de um desafio, que é estar à frente da aplicação de aulas, planejamento e regência de conteúdos que os alunos apresentam dificuldade de aprendizagem.

Obteve-se com a atividade realizada, um excelente resultado, demonstrando que o jogo foi muito eficaz, possibilitando um momento de descontração, divertimento e compartilhamento de conhecimentos entre os grupos e alunos diferentes.

\section{REFERÊNCIAS BIBLIOGRÁFICAS}


BNCC, Base Nacional Comum Curricular do Ensino Médio. Acesso em 10 fevereiro de

http://portal.mec.gov.br/index.php?option=com_docman\&view=download\&alias $=8512$ 1-bncc-ensino-medio\&category_slug=abril-2018-pdf\&Itemid=30192

CRESPO, L. C.; GIACOMINI, R. As atividades lúdicas no ensino de química: uma revisão da revista química nova na escola e das reuniões anuais da sociedade brasileira de química. Disponível em: http://abrapecnet.org.br/atas_enpec/viiienpec/resumos/R0758-1.pdf. Acesso em: 13 março de 2019.

CUNHA, M. B. da. Jogos no Ensino de Química: Considerações Teóricas para sua Utilização em Sala de Aula. Química Nova na Escola, v. 34, n. 2, p.92-98, 2012.

FERREIRA, E. A.; GODOI, T. R. A.; SILVA, L. G. M. da; SILVA, T. P. da; ALBUQUERQUE, A. V. de. Aplicação de jogos lúdicos para o ensino de química: auxilio nas aulas sobre tabela periódica. In: Encontro Nacional de Educação, Ciência e Tecnologia UEPB, 1., 2012, Campina Grande. Anais do Encontro Nacional de Educação, Ciência e Tecnologia UEPB. Campina Grande: Realize Eventos e Editora, v. 1, p. $1-10,2012$.

FERNANDES, L.D.; FURQUIM, A.A.; BARANAUSKAS, M.C.C. Jogos no Computador e a Formação de Recursos Humanos na Indústria. In: VI Simpósio Brasileiro de Informática na Educação, 1995, Anais... Florianópolis, SC, 1995.

GRANDO, R. C. O. O jogo na educação: aspectos didáticos-metodológicos na educação matemática. Tese de Doutorado, Universidade Estadual de Campinas, Campinas, 2001.Disponivel em:http://www.cempem.fae.unicamp.br/lapemm ec/cursos/el654/2001/jessica_e_paula/JOGO.doc.

LISBOA, J. C. F. Ser protagonista: química, $2^{\mathbf{0}}$ ano: ensino médio / Julio Cezar Foschini Lisboa... [et al.]; organizadora Edições SM; editora responsável Lia Monguilhott Bezerra. - São Paulo: Edições SM, 2016. - (Coleção ser protagonista).

MARCELINO, N. C. Estudos do lazer: uma introdução. Campinas. São Paulo: Autores Associados, 1996.

OLIVEIRA, S. R.; GOUVEIA, V. P.; QUADROS, A. L. Uma reflexão sobre aprendizagem Escolar e o Uso do Conceito de Solubilidade/Miscibilidade em Situações do Cotidiano: Concepções dos Estudantes. Química Nova na Escola, 2009. Acesso em 12 dezembro 2019, http://www.qnesc.sbq.org.br/online/qnesc28/09-AF-1806.pdf.

QUEIROS, J. A.; ROCHA, W. C.; YAMAGUCHI, K. K. L. Atividades lúdicas como ferramenta para o ensino da teoria atômica atômica. Scientia Amazonia, v. 7, n.3, E1E6, 2018. 
SCHNETZLER, R.P. Concepções e alertas sobre formação continuada de professores de Química. Química Nova na Escola, v.16, n.1, 2002. Acesso em: 10 ago. 2019. http://qnesc.sbq.org.br/online/qnesc16/v16_A05.pdf 